\title{
China’s Elia: A Study of Liang Yuchun’s Translation Activities
}

\author{
JING Su-rong \\ School of Foreign Languages of Shanxi University, Taiyuan, Shanxi, China 030006
}

\begin{abstract}
Liang Yuchun, who once played an important role in introducing and translating foreign literature (especially English essays) in the 1920s \& 1930s, has been hitherto much neglected by the research field of translation studies. The present study first gives a general description of Liang's translation practices, the exploratory analysis of his motivation and the collection of his thinking on translation. Based on that, the author explores the influences of Liang's translation activities from the point of view of media translatology, thus proposing that Liang Yuchun should be given a deserved position in the history of Chinese translation literature.
\end{abstract}

Keywords: Liang Yuchun, translation activities, influences, a literary position

\section{Introduction}

In the 1920s and 1930s, the May Fourth Movement was already over, but the influence of literary revolution still lingered on. The various genres of Chinese literature were all undergoing modernization and prose was no exception. While inheriting optionally the domestic tradition, modern Chinese literature took in fresh nutrients from its foreign counterparts with translation as the major approach. Among many others, Liang Yuchun was the most diligent translator whose writing was most influenced by his translation of foreign literature.

\section{A Short Biography of Liang Yuchun}

In 1906, Liang Yuchun was born in an intellectual family in Fuzhou, Fujian Province. In 1918, he passed the autumn examination and was admitted into No. 1 Middle School of Fujian Province (present No. 1 Middle School of Fuzhou). Upon graduation in summer of 1922, Liang Yuchun went to Shanghai and sat the entrance examination of English Department of Peking University. With excellent results, he was enrolled in preparatory classes there. After two-year preparatory study, Liang Yuchun was formally admitted into the undergraduate program in 1924 and graduated in the summer of 1928. After a short period of teaching at Peking University, Liang Yuchun went southbound to Jinan University, Shanghai and worked as a teaching assistant in English Department. In the beginning of 1930, he returned to Peking University and worked both as a teacher and a librarian. On June 25, 1932, Liang Yuchun died of scarlet fever in Beijing at the age of 27

Liang Yuchun is remembered as an essayist in the history of modern Chinese literature. In his short lifespan, however, Liang Yuchun produced far more translations than essays. We may even say it was by means of translation that he embarked on the career as an essay writer. To him, translation activities not only permeated throughout his literary career, but also exerted great impact upon the formation of his outlook on world and life.

JING Su-rong, Ph.D., Associate Professor, School of Foreign Languages of Shanxi University. 
Since translation has virtually laid a solid foundation for his reputation as an essayist, the author thinks it is of great significance to take as the object of study Liang Yuchun's translation activities.

However, little research has been done in the very field. As an important essay translator and writer in the 1920s and 1930s, Liang Yuchun's translation activities and works had scarcely attracted attention from the literature until the beginning of this century when there appeared only a few articles involving some relevant discussions that were far from enough in depth and width. In view of the status quo, the present study makes proper use of the existing research results and gives a much fuller account of Liang Yuchun's translation activities and works in the hope of compensating the above-mentioned scarcity in the very field of study.

\section{An Overview of Liang Yuchun's Translated Works}

Roughly speaking, Liang Yuchun was engaged in translation mainly from 1926 to 1932. While carrying out essay writing within the less than six years, Liang produced and published 36 translated works in total (27 books and 9 magazine articles), the majority of which consists of fiction and prose.

\subsection{Fiction}

Liang Yuchun produced altogether 12 works of fiction in such genres as short story, novella, novel and epistolary novel. In chronological order the authors and names of these works are: (1) Turgenev, Yakov Pasynkov (novella), Shanghai: Beixin Publishing House (BXPH for short below), 1928; (2) Garshin, The Red Flower (short story), BXPH, 1930 (1st edition); (3) W. H. White, Esther (epistolary novel), BXPH, 1930 (1st edition); (4) G. R. Gissing, The Poet's Portmanteau, BXPH, 1931; (5) E. C. Gaskell, The Old Nurse's Story (novella), BXPH, 1931; (6) Thomas Hardy, The Three Strangers (short story), BXPH, 1931; (7) M. Gorky, In the Steppes (The Khan and His Son included, short stories), BXPH, 1931; (8) Joseph Conrad, Youth (novella), BXPH, 1931; (9) Daniel Defoe, Robinson Crusoe (novel), BXPH, 1931; (10) Daniel Defoe, Moll Flanders (novel), BXPH, 1931; (11) Valentine Kataev, Things (short story), Youth Circle, 1931(1):231-240; (12) Joseph Conrad, Lord Jim (novel) (posthumous), Shanghai: Commercial Press, 1934.

As we can see, four of the above-mentioned works [(1)(2)(7)(11)] are written by Russian writers and the rest eight are all by English ones. Besides, the first eight are all English-Chinese bilingual editions while in the last four works only Chinese translations are available.

\subsection{Prose}

Of all Liang Yuchun's translation works, English essays are most prodigious. In total, he translated 47 English essays, which are respectively collected in the following five bilingual anthologies of English essays:

(1) English Essays, Shanghai: The Kaiming Book Co., Ltd., 1928.

It contains the translator's preface and 10 essays whose writers and titles are as follows: Richard Steele, $\mathrm{Mr}$. Bickerstaff Visits a Friend; Joseph Addison, On the Excessive Care of Health-Letter of the Valetudinarian; Oliver Goldsmith, The Man in Black; Charles Lamb, Detached Thoughts on Books and Reading; William Hazlitt, On the Feeling of Immortality in Youth; Leigh Hunt,Watchmen; Logan Pearsall Smith, The Rose; W. H. Hudson, The Samphire Gatherer; Robert Lynd, This Body; Sir Walter Raleigh, Don Quixote.

(2) Some Best English Essays, Shanghai: Beixin Publishing House, 1930. 
It contains the translator's preface and 20 essays whose writers and titles are: Richard Steele, On Conjugal Happiness; Joseph Addison, On Practical Jokes; Samuel Johnson, On Sorrow; Oliver Goldsmith, Happiness is a Great Measure Dependent on Constitution; Charles Lamb, A Bachelor's Complaint of the Behaviour of Married People; William Hazlitt, On the Fear of Death; Leigh Hunt, In Prison; John Brown, Her Last Half-crown; A. G. Gardiner, A Fellow Traveller; John Galsworthy, Evolution; E. V. Lucas, London Mysterious; Hilaire Belloc, On a Hermit Whom I Knew; G. K. Chesterton, On Running After One’s Hat; George W. E. Russell, The Scholar; John Middleton Murry, Fact and Fiction; Roger Wray, Autumn; Robert Lynd, Trains; E. Temple Thurston, Ship's Logs; A. A. Milne, The Chase; Holbrook Jackson, The Spirit of the Dance.

(3) Meeting ${ }^{1}$, Shanghai: Beixin Publishing House, 1930.

It contains four essays written by John Galsworthy, namely A Green Hill Far Away, Romance-Three Gleams, Felicity and Meeting.

(4) Our Village: Sketches of Rural Character \& Scenery, Shanghai: Beixin Publishing House, 1931.

It contains three essays written by Mary Russell Mitford, namely The Old Gipsy, The Young Gipsy and The Fall of the Leaf.

(5) More Best English Essays², Shanghai: Beixin Publishing House, 1935.

It contains the translator's preface and 10 essays whose writers and titles are: Abraham Cowley, Of Solitude; David Hume, Of the Dignity or Meanness of Human Nature; Charles Lamb, New Year's Eve; Dream Children: a Reverie; William Makepeace Thackeray, On a Hundred Years Hence; Alexander Smith, On Death and the Fear of Death; Richard Jefferies, Meadow Thoughts; Augustine Birrell, Actors; Alfred George Gardiner, On Talking to One's Self; Edward Verrall Lucas, The School for Sympathy.

Besides fiction and prose, Liang also translated poetry, drama, philosophical papers and literary biographies.

\section{An Analysis of Liang Yuchun's Translation Motivation}

As we know, translation studies should not only pay attention to the micro cultural background information, that is, the intention, quality and choice of the translator, but also to the macro one which involves the social, economic, political and cultural context at that time. To understand Liang Yuchun's translation motivation, we might as well first put our eyes on the macro cultural background of his era.

In 1924, Liang Yuchun entered the Department of English of Peking University. Then he started his translation practice in 1926 and died in the summer of 1932. At that time, the construction of new literature, which began in the early 20th century, had entered a relatively stable period of development. In carrying out this task, the foresighted modern intellectuals clearly realized the shortcomings of traditional Chinese literature and tried to transform it by introducing the advanced elements of western literature. It is under such a background that the creation theory of English essays and famous works were introduced into China. It is also in such a macro cultural environment that Liang Yuchun began to translate English essays systematically. His translation motivation can be said to reflect the translation trends of his time, to which his own words bear witness:

\footnotetext{
${ }^{1}$ This English title is retranslated from Liang’s Chinese translation (《幽会》) by the author. The original English title is still to be retrieved.

2 This English title is retranslated from Liang’s Chinese translation (《小品文续选》) by the author. The original English title is still to be retrieved.
} 
I just hope... there can be a kind of essay with a Chinese touch in the world essays, which may be my motivation to translate this collection of essays regardless of my clumsiness. (Wu, 1992, p. 436)

Before Liang joined the translation team of British essays in China then, most translations of British essays appeared in various literary and art journals separately and there were few published collections. Therefore, Liang Yuchun's centralized and systematic translation of English essays is particularly remarkable. So how could he be so outstanding? In addition to his personal subjective efforts, the prosperity of modern publishing industry at that time provided an important practical guarantee.

The result of the East learning from the West in the middle and late 19th and the early 20th century was to hasten the modernization of Chinese society. In this process, the modern publishing industry formed and became a necessary condition for the dissemination of new ideas and theories. A number of young publishing institutions began to emerge, which, in line with the requirements of the times, took the publishing of new literature and art books and the translation of foreign literature as their own responsibilities. Among many others, Shanghai Beixin Publishing House (BXPH) was a prominent representative.

BXPH was founded on March 15, 1925, which was symbolized by the publication of Lu Xun's translation of Kuriyagawa Hakuson's “The Symbol of Anguish”3. Different from the Commercial Press and other large publishers, BXPH was not a conventional publisher and it took a more open and tolerant attitude toward both mainstream and non-mainstream scholars of all schools, thus making possible the presence of many new authors. For budding ones, the company also tried to publish as many books as possible, cultivating their reputation through reviews, advertising, and inclusion of their works in the series. From the perspective of literary sociology, publishing series is profitable. Books published in series shared a common orientation and a uniform expression way and interest, thus being able to follow and satisfy the readers' unceasingly changing needs (Yu, 2006, pp. 81-82). Meanwhile, the publication of series could also provide a good platform for publishing translations. And Liang Yuchun was one of those translators who benefit from such a platform. His translations of British essays had all been included in series. English Essays was included in "Kaiming English-Chinese Annotated Translation Series”; Some Best English Essays and More Best English Essays were included in “Self-study English Series”; Meeting and Our Village were included in "Small English Series".

To sum up, the need of social development and the flourishing of the media cultivated Liang Yuchun's clear translation motivation and provided a strong realistic guarantee for its materialization.

\section{A Summary of Liang Yuchun's Views on Translation Issues}

Liang Yuchun's ideas about translation activities are scattered in the prefaces or epilogues of his translations, but shining with their uniqueness. After gleaning and sorting, we find that Liang's translation views are mainly concerned with the following four aspects.

\subsection{The Purpose of Translation}

In the middle and late 1920s and early 1930s, China's social and cultural background was full of demand for translation activities on the whole. From the translation of foreign literary works, the general public gained new

\footnotetext{
3 This English title is retranslated from Lu Xun’s Chinese translation (《苦岮的象征》) by the author. The commonly-recognized English title is still to be retrieved.
} 
and different life experiences, and their ideas had been constantly updated. Modern writers also drew rich nutrition from translated works, thus effectively promoting the literary revolution and the development and maturity of new literature. In such a cultural context, the expected function of a translated literary text was mainly to provide valuable information for the literary development and innovation of the era and a platform for the target language readers to understand foreign cultures, thus making them learn useful knowledge while having fun in reading literary works, better understand the cultural characteristics of their own culture, and serve the language and culture construction of the nation.

In such a social and cultural background, as a young translator, Liang Yuchun experienced a change of his understanding of the purpose of translation from vague to explicit in just a few years. When he took over the translation of "Yekhov Panshinkov", the very first translated work of his, Liang Yuchun had no purpose at all but to complete a task that had to be done, which can find evidence in his own words:

In the winter of the year before last (1926) I translated a Turgenev novel, which I did not particularly like to read, in a muddling state. Come to think of it now, I don't know I should laugh at myself or feel ashamed sighing. Or maybe just forget it! (Liang, 1928, p. 2)

Such a "muddling state" began to change two years later. In September 1928, English Essays was published. In the translator's preface, Liang Yuchun explained that he "felt depressed in April and May this year and so chose to do some translation to get relieved” (Liang, 1928, p. 2). This time, he was no longer blindly doing translation; instead, he began to have a purpose, that is, to meet his personal interests, kill time and mediate mood. In 1930, Liang Yuchun compiled a second translation collection, Some Best English Essays. In the preface, he explicitly stated that he hoped that through the translation of British essays, "there could be a Chinese style of essays in the world essays in the future” (Wu, 1992, p. 436). Such a clear purpose is also reflected in his third collection of essays, Some More Best English Essays:

The selection of essays I compiled two years ago was mostly sentimental. In comparison, this sequel is more ideological. (Liang, 1935, pp. 1-2)

In short, we think that Liang Yuchun's gradually clearer understanding of the purpose of translation is actually a process of gradually recognizing and agreeing with the aforementioned role played by translation in the social and cultural development at that time.In this process, Liang Yuchun gradually came to regard translation as a way and means to achieve a certain realistic goal, showed a clear sense of responsibility, and selectively translated and introduced foreign literary works, especially English essays, thus becoming the backbone of the English prose translation craze in the 1920s and 1930s.

\subsection{The Path to Translation}

In the 1920s and 1930s, the indirect translation path, that is, translating foreign works from their Japanese or English versions, which had been dominant since the late Qing Dynasty, began to be criticized and censured from various aspects by theorists with different starting points. However, the reality of China's social and cultural development at that time urgently required the wide introduction of literary works from all over the world, especially those of the oppressed and weak ethnic groups, and China was extremely short of talents who knew related languages. Therefore, those foreign languages which many more people knew well, such as English and 
Japanese, served as the intermediate means of other foreign languages few people knew, which made the indirect translation path still play an important role in the translation of foreign literature.

In the above-mentioned social and cultural background, Liang Yuchun's translation activities showed an explicit tendency to follow the times, that is, with the direct translation path dominating, the indirect translation one held a non-negligible position. Of the 36 translations of Liang Yuchun, 90\% are direct translations, all by British writers. There are four works produced through the indirect translation path, accounting for about $10 \%$. All of them are the works of Russian writers. It can be seen that Liang Yuchun fully demonstrated his linguistic advantages in English through the direct translation of British writers’ works, which promoted the translation and dissemination of English literature in China, and complied with the development trend of translation activities in the society at that time. On the other hand, Liang Yuchun's translation and introduction of Russian works through English met the realistic needs of social and cultural development at that time.

In a word, judging from the translation results, Liang Yuchun resorted to the direct and the indirect translation path at the same time.Ideologically speaking, he also had a clear understanding in this respect:

...as its name indicates, the indirect translation, of course, will result in the loss of a lot of original verve, but we do not have the opportunity and ability to understand more than a dozen languages, so we have to rely on it to have a glimpse of the trend of various countries' sketch literature. (Wu, 1992, p. 272)

Although he talked about sketch literature only, it is clear that Liang Yuchun had a clear understanding of the realistic necessity of the indirect translation path and held an objective and pragmatic attitude toward it.

\subsection{The Criteria of Translation}

In 1898, Yan Fu, a famous scholar of the late Qing Dynasty, put forward the famous theory of "faithfulness, expressiveness and elegance" in "Preface to Evolution of Ethics". Until the 1920s and 1930s, the discussion on translation criteria was still basically centered on the three-word principle, but there were different opinions on it. Some fully agreed with it. Some were in favor generally or did not oppose basically, but thought that it should be appropriate to revise or supplement. Still some held a totally negative attitude toward it.

Of course, during the period when Liang Yuchun was engaged in translation activities, the discussion on translation criteria was not limited to "faithfulness, expressiveness and elegance”. Many translators and scholars put forward their unique viewpoints (e.g., Lu Xun, Qu Qiubai, Zheng Zhenduo, etc.), but all these theories, implicitly or explicitly seemed to have been influenced by the three-word principle. Most translators even took it as the norm and tried their best to follow in translation practice. Living in such a translation theoretical environment, although he had not explicitly talked about translation standards, Liang Yuchun was on the side of those who favored in the principle. Such a position can be easily found in some of his writings:

The English version by Florio is too archaic in diction while Cotton's translation is no better. Recently Oxford University Press published another version by E. J. Trechmann. It is expressive and elegant. As for its faithfulness, I don't even have the courage to check it against the original text since the latter was written in the 16th-century French. (Liang, 1928, pp. 28-29)

It can be seen that Liang Yuchun obviously adopted the standards of "faithfulness, expressiveness and elegance" when evaluating the quality of translation. As for whether he has his own unique understanding or interpretation of the three-word theory, there has not yet any relevant material available for the time being. 


\subsection{The Style of Translation}

In the discussion of translation standards around "faithfulness, expressiveness and elegance", the issue of the style of translation has also become a hot topic due to the existence of "elegance" and people's different understandings of its meaning. As far as the Chinese translation circle in the 1920s and 1930s is concerned, it is generally accepted that the translation should try its best to convey the original style and the translator should try his best to avoid his own style. In this respect, Liang's views are basically in line with the mainstream ones:

This collection's most lauded point is that quite a few masterpieces, such as Gogol's The Coat and Garshin's The Red Flower, have been re-translated more faithfully. Compared with old versions in other anthologies, they have indeed retained more of the author's charm. But some places still read unnatural, which is inevitable, since nothing under the sun is to be found without fault. (Wu, 1992, pp. 279-280)

According to Liang Yuchun, a translation cannot be considered good if it does not clearly convey or preserve the charm of the original text. However, nothing is perfect, so it is impossible to completely convey and preserve the original charm. Based on this view, while paying attention to preserving the original charm, Liang Yuchun also has a clear understanding of whether the translation should have the translator's own style:

I received your book the day before yesterday. I read your translation as if I were reading your letter because your own style has been more or less integrated into your translation. As far as I am concerned, a good translation is always imbued with the taste of the translator. If the translator does not penetrate himself into the translated work, he can never convey the charm of the author. Since he walks into the work, the translation will certainly have the color of the translator. Omar translated by Fitzergald is a case in point. (Li \& Tang, 1995, p. 146)

In the quotation, Liang Yuchun gives a positive comment on the existence of the translator's style in translation, from which it is not difficult to see that Liang Yuchun is not in favor of suppressing the translator's style in literary translation. At this point, we may say that Liang Yuchun's understanding has a certain foresight beyond the mainstream translation view of the times.

In addition to the above four aspects, Liang Yuchun also has his own understanding of other issues involved in translation. For example, he once made it clear that the selection of translation materials should consider the readers' taste and the influence of readers' taste on the translation method. In the prefaces, postscripts or annotations of his translated works, he also discussed the translation of proper names and expressed his clear appreciation for the translation method of retaining both sound and meaning.

To sum up, because of the few written materials left by Liang Yuchun, little can be known about his translation views. But even so, we can still feel that this diligent and thoughtful young translator had formed a clear view on translation in the process of translation practice in just a few years. If given more years of living, wouldn't he have formed a translation theory of his own as unique as his thoughts about essay creation?

\subsection{The Influence of Liang Yuchun's Translation Activities}

During the boom of translation and introduction of English essays in China in the 1920s and 1930s, Liang Yuchun was the most diligent and devoted translator. He translated three anthologies of English essays which are 47 in total and involve 29 authors. His understanding of English essays is generally regarded as the most thorough and comprehensive, and his excellent discussion on the creation of essays is scattered in the prefaces and notes of his three essay collections. It is of great theoretical value to the study of modern Chinese prose. 
Besides his translation of foreign works, Liang’s introduction to British writers is also considered to be ahead of the times. His comments on Charles Lamb in particular stands out. After the May 4th movement in 1919, Lamb had an important influence on many Chinese modern prose writers. However, most poets and writers read and studied Lamb through the original English works. For example, the famous writer Feng Yidai once wrote an article titled "Benefiting from Lamb" and talked about his experience of learning from Lamb in prose writing. By contrast, Liang Yuchun not only read Lamb, but also translated his works so well that he was even known as “China's Elia” (Liu, et al, 2006, p. 412) (Elia is the pseudonym of Lamb). The article he wrote for commemorating Lamb, “A Critical Biography of Charles Lamb” has become an important part of literature in the studies of Lamb and his translation in China. Liu Bingshan, a famous contemporary English prose translator, once commended in the preface of Selected Essays of Elia that his translation of Lamb's essays was actually “a continuation of the translation of Lamb initiated by Liang Yuchun” (Liu, 1987, p. 16). It may be safe for us to say that Liang Yuchun started a career of translating British essays on a large scale in China.

Judging from the perspective of medio-translatology, Liang Yuchun's translation and introduction of several writers' works is of great significance. As historical records show, Liang Yuchun is the first translator to introduce the prose works of John Galsworthy and Mary Russell Mitford into China. In addition, he also first translated the short story The Red Flower by Russian writer Vsevolod Mikhaylovich Garshin, the short story The Old Nurse's Story by British writer Elizabeth Gaskell, the short story The Poet's Portmanteau by George Gissing, and the epistolary novel Esther by William Hale White, W. N. P. Barbellion's A Last Diary, John Hankin's one-act play The Constant Lover, Daniel Defoe's Moll Flanders as well as Joseph Conrad's Youth and Lord Jim. ${ }^{4}$ Among these works, Liang Yuchun's first translation of Conrad's works can be said to be the translator's conscious choice, which is particularly valuable for a young translator. In this respect, the famous scholar Hu Shi once made special mention of Liang's effort in the editor's postscript of "Lord Jim":

I strongly encouraged Mr. Liang Yuchun (whose pseudonym is Qiu Xin) to translate a complete collection of novels by Conrad. Unfortunately, Mr. Liang fell victim to an epidemic last year. Not only did China lose a young writer with great literary interest and talent, but Conrad's novels also lost a loyal and enthusiastic translator, which is what makes us sad most. (Liang, 1934, the editor's notes)

In a word, Liang Yuchun's translated works are mainly English literary works, most of which are famous works by famous writers. Basically reflecting the temporal theme of "writing for the sake of life", those works involve a variety of genres with remarkable artistic characteristics. It can be said that Liang Yuchun's translation activities constitute an organic part of the history of Sino-British literary exchanges and play a positive role in the dissemination, reception and reshaping of English literature in China.

In addition, Liang Yuchun's translated works are of great historical value for the studies of Chinese literary history and modern Chinese literature. Because of the foreignization-oriented translation strategy, the narrative language of Liang Yuchun's translation works is the modern vernacular Chinese with a strong European flavor, presenting a reality that modern Chinese once had in the development process. The high heterozygotic degree of Liang's translation language also reflects the unequal cultural relationship between English and Chinese

\footnotetext{
${ }^{4}$ Liang Yuchun only translated the first 15 chapters and did not finish the translation before he died.The latter eight chapters was completed by his classmate Yuan Jiahua.
} 
presented through translation at that time. In this sense, Liang's translation is a real corpus worthy of researchers' attention.

\section{Conclusion}

At the beginning of this article, we mentioned that Liang Yuchun has been known as an essayist in the circle of modern Chinese literature, but his identity as a translator is rarely known. This, as we see, is very unfair to Liang Yuchun who once produced so many translations and exerted great influence in many aspects.

In terms of translation practice, Liang's diligence in translation is no less than that of Lu Xun, Zhou Zuoren and others of the older generation as well as that of his peers like Zhang Yousong and Fu Donghua. In terms of genres of his translations, Liang Yuchun's most effective effort was the translation of English essays. He translated the most English essays at that time and gained from translation the most profound understanding of the creation of essays. The related theoretical ideas thus formed were outstanding among his peers. In terms of translation thoughts, although due to premature death, Liang Yuchun did not form systematic and mature translation thoughts, but some of his discourses we have sorted out are of important theoretical value. For example, Liang Yuchun had a clear idea of the relationship between "the charm of the author", "the style of the translator" and "the taste of the readers", which exhibits well his theoretical potential. In terms of the reception effect, several of his translations had been well recognized by the reception environment of his time. According to Feng Zhi, a famous poet and translator, "some college students who studied English literature in the 1930s and 1940s were still happy to say when they were old that they had benefited a lot from the English-Chinese translation of Some Best English Poems compiled and translated by Liang Yuchun” (Feng, 1984, p. 109). It can at least partially show that Liang Yuchun's translation works have had a positive influence on later generations.

When talking about Liang's essays, the famous writer Fei Ming once said, "his achievement is not visible, and only a few close friends know that he has brewed a good momentum” (Fei, 1979/1995, p. 220). When it comes to Liang's translations, we can also say that he had just "brewed a good momentum”. He died prematurely before he had time to fully show his talent in translation. But even so, his meteor-like short but extremely bright youth is still worth our treasure and appreciation. We sincerely hope that in the future when we rewrite the history of Chinese translation literature, we will include Liang Yuchun and give him his due.

\section{References}

Fei, M. (1979/1995). Preface I to tears and laughter. In X. C. Qin (Ed.), Essays by Liang Yuchun. Taipei: Hongfan Bookstore. Feng, Z. (1984). On Liang Yuchun. Historical Studies of Modern Literature, (1).

Li, B. F. (1995). Tang Yinsun. Forty-one letters from Liang Yuchun to Shi Min. Historical Studies of Modern Literature, (4).

Liang, Y. C. (1928). English essays. Shanghai: Kai Ming Bookstore.

Liang, Y. C. (1935a). Lord Jim. Shanghai: Commercial Press.

Liang, Y. C. (1935b). Some more best English essays. Shanghai: Beixin Book Company.

Liu, B. S. (Trans.). (1987). Selected essays by Elia. Beijing: Sanlian Bookstore.

Liu, J., et al. (2006). Modern and contemporary Chinese literature study guide. Nanjing: Nanjing University Press.

Wu, F. H. (1992). A complete compilation of Liang Yuchun's essays. Hangzhou: Zhejiang Literature and Art Publishing House. Yu, J. L. (2006). The sociological study of translation. Shanghai: Shanghai Translation Publishing House. 